\title{
Prevalence of putative virulence factors and antimicrobial susceptibility of Enterococcus faecalis isolates from patients with dental Diseases
}

\author{
Randa Salah ${ }^{1}$, Najla Dar-Odeh², Osama Abu Hammad² and \\ Asem A Shehabi*1
}

\author{
Address: ${ }^{1}$ Department of Pathology-Microbiology, Faculty of Medicine and Faculty of Dentistry, University of Jordan, Amman, Jordan and \\ ${ }^{2}$ Department of Oral Surgery-Medicine, and Periodontics, University of Jordan, Amman, Jordan \\ Email: Randa Salah - randasalah@yahoo.co.uk; Najla Dar-Odeh - Najla@ju.edu.jo; Osama Abu Hammad - deoaah@ju.edu.jo; \\ Asem A Shehabi* - ashehabi@ju.edu.jo \\ * Corresponding author
}

Published: I June 2008

BMC Oral Health 2008, 8:17 doi:10.1 I86/1472-6831-8-17

This article is available from: http://www.biomedcentral.com//472-683I/8/17

(C) 2008 Salah et al; licensee BioMed Central Ltd.

This is an Open Access article distributed under the terms of the Creative Commons Attribution License (http://creativecommons.org/licenses/by/2.0), which permits unrestricted use, distribution, and reproduction in any medium, provided the original work is properly cited.
Received: 4 August 2007

Accepted: I June 2008

\begin{abstract}
Background: This study investigated the prevalence of Enterococcus faecalis, its putative virulence factors and antimicrobial susceptibility in individuals with and without dental diseases. A total of 159 oral rinse specimens were collected from patients $(n=109)$ suffering from dental diseases and healthy controls $(n=50)$.
\end{abstract}

Results: $E$. faecalis was detected using only culture in $8 / 109(7.3 \%)$ of the patients with various types of dental diseases, whereas no $E$. faecalis was found in the healthy controls weather using both culture and PCR. Phenotype characterizations of the $8 \mathrm{E}$. faecalis isolates indicated that $25 \%$ of the isolates produced haemolysin and $37.5 \%$ produced gelatinase. Most important virulence genes; collagen binding protein (ace) and endocarditis antigen (efaA) were present in all $8 \mathrm{E}$. faecalis isolates, while haemolysin activator gene (cylA) was detected only in $25 \%$ of isolates, and all isolates were negative for esp gene. All E. faecalis isolates were $100 \%$ susceptible to ampicillin, chloramphenicol, ciprofloxacin, vancomycin, and teicoplanin, and to less extent to erythromycin (62.5\%).

Conclusion: This study shows that all $E$. faecalis isolates were recovered only from patients with dental diseases especially necrotic pulps, and all isolates carried both collagen binding protein and endocarditis antigen genes and highly susceptible to frequently used antimicrobial drugs in Jordan.

\section{Background}

Many studies demonstrated that E. faecalis is frequently found in patients suffering from oral infections like gingivitis, periodontitis, teeth with failed endodontic as well as acidic carious lesions associated with persistently infected root canals. [1-4] Other studies demonstrated the frequent presence of $E$. faecalis in association with a wide variety of aerobic and anaerobic bacterial species involved in various endodontic diseases and chronic apical periodontitis [4-7].

Virulent factors of E. faecalis include adherence to host tissue, invasion and abscess formation, modulation of host inflammatory responses, secretion of various products 
which enhances biofilm formation [8-10]. Data on oral prevalence of $E$. faecalis and its virulence factors vary from one study to another $[1,6,7]$. Therefore, more investigation on potential virulence factors of $E$. faecalis would be useful in understanding their role in dental infections. Moreover, clinical isolates of E. faecalis recovered from root canal infections can express antimicrobial resistance to conventional treatment regimens recommended for dental procedures [11-13].

This study aimed to investigate the occurrence of $E$. faecalis, its virulence factors and antimicrobial susceptibility in association with and without some dental diseases in a Jordanian population.

\section{Results}

Age of the patients ranged from 14 to 75 years (mean; 36.4 year), and the control persons were between 20 and 69 years (mean; 28.3 year). The prevalence of $E$. faecalis isolates in oral rinse specimens of patients with dental diseases was 8/109 (7.3\%) using both culture and PCR tests, whereas all oral rinse specimens obtained from the 50 healthy control persons were negative for $E$. faecalis using both methods. All DNA extracted from $8 \mathrm{E}$. faecalis isolates were proved to be positive for specific $E$. faecalis $16 \mathrm{~s}$ rRNA gene. The difference between the results of the two groups is statistically significant $(\mathrm{P}$ value $=0.031)$. In addition, there was 2 E. avium isolates (Table 1). The growth pattern of $E$. faecalis isolated from positive cases varied from few to numerous colonies $\left(2-50 \times 10^{3}\right.$ colonies $/ \mathrm{ml}$ ). The distribution of 8 E. faecalis isolates among patients in association of sex, smoking, oral hygiene and dental diseases is shown in (Table 2). Detection of putative virulence factor genes among $8 \mathrm{E}$. faecalis isolates using PCR were as follows; both ace and efaA genes were present in all isolates (100\%), while cylA gene was detected only in 2 isolates, and all isolates were negative for esp gene (Table 3, Figure 1). All 8 E. faecalis isolates were $100 \%$ susceptible to, ampicillin, chloramphenicol, ciprofloxacin, teicoplanin and vancomycin, while $62.5 \%$ and $12.5 \%$ of the isolates were susceptible to erythromycin, imipenem, respectively, and all were resistant to gentamicin, clindamycin and Oxacillin

\section{Methods}

A total of 159 subjects who were attending the Dental clinic/Jordan University Hospital (JUH), Amman, Jordan were examined for presence of dental diseases by two dentists (N. Dar-Odeh \& O. Abu Hammad) during the study period of 2005. Subjects were divided into two groups according to the presence or absence of dental diseases. Control group consisted of 50 healthy persons who do not have any obvious dental disease. Dental diseases investigated include: dental caries, plaque-induced gingivitis, and root canal disease. Personal data, smoking history, presence or absence of clinical dental disease, oral hygiene and antibiotic treatment during the last month were recorded for each examined person. Dental caries and gingivitis were recorded as present/absent. Root canal disease included: irreversible pulpitis, necrotic pulp only, and periapical periodontitis. Oral hygiene was considered as either poor or good according to plaque index. All patients and control persons had given their written consent to be included in the study. All patients and controls were asked to rinse their mouths for 60 seconds with 10 $\mathrm{ml}$ sterile distilled water and returned the oral rinse to a sterile container.

\section{Specimens Processing}

All specimens were transferred immediately to the Microbiology Research Laboratory/Faculty of Medicine/University of Jordan. Oral rinse specimens were poured into sterile tube and centrifuged for $10 \mathrm{~min}$ at $10,000 \mathrm{~g}$. The supernatant discarded and the remaining pellets were resuspended by vortex in one $\mathrm{ml}$ of sterile normal saline $0.9 \%[14]$.

\section{Isolation of Enterococcus species}

A loop full of the suspended pellets $(0.01 \mathrm{ml})$ was cultured on bile-esculin agar plates to detect and count the presence of gray to black colonies of Enterococcus species. The rest of the suspended specimens were stored at $-70^{\circ} \mathrm{C}$ for further investigations. At least three colonies grown on bile-esculin plates were sub-cultured into blood agar plates to isolate Enterococcus species (Oxoid, England). All cultures carried out through the study were incubated in a candle jar $\left(5 \% \mathrm{CO}_{2}\right)$ for $24-48 \mathrm{hrs}$ at $37^{\circ} \mathrm{C}$. Pure growth obtained from blood agar plates was again inoculated onto Cysteine Lactose Electrolyte Deficient (CLED) agar

Table I: Detection of Enterococcus species in patients and controls

\begin{tabular}{ccc}
\hline Characteristics & 109 Patients with dental diseases No. (\%) & 50 Controls persons No. (\%) \\
\hline Age mean (years) & $36.4 \pm 13.98$ & $28.3 \pm 12.59$ \\
Sex & $39(36)$ & $24(48)$ \\
Male & $70(64)$ & $26(52)$ \\
Female & $8(7.3)$ & 0 \\
E. faecalis & $2(1.8)$ & 0
\end{tabular}


Table 2: Distribution of $8 \mathrm{E}$. faecalis isolates in association of sex, smoking, oral hygiene and dental diseases among 109 patients

\begin{tabular}{|c|c|c|c|c|}
\hline Characteristics & Positive E. faecalis* & Negative E. faecalis* & Total No. & P-value $* * *$ \\
\hline Female & 7 & 63 & 70 & 0.134 \\
\hline Male & 1 & 38 & 39 & \\
\hline Nonsmoker & 7 & 83 & 90 & 0.228 \\
\hline Smoker & 1 & 18 & 19 & \\
\hline Poor Oral hygiene & 7 & 68 & 75 & 0.222 \\
\hline Good Oral hygiene & I & 33 & 34 & \\
\hline Gingivitis +ve & 7 & 64 & 71 & 0.161 \\
\hline Gingivitis -ve & 1 & 37 & 38 & \\
\hline necrotic pulps & $8 * *$ & 101 & 109 & 0 \\
\hline caries +ve & $4^{* *}$ & 77 & 81 & 0.115 \\
\hline Caries -ve & 4 & 24 & 28 & \\
\hline
\end{tabular}

*colony count: $2-50 \times 10^{3}$ colonies $/ \mathrm{ml}$.

** Each one patient was treated with antibiotics during the last month.

*** Not significant between positive $E$. faecalis and each of sex, smoking, oral hygiene, gingivitis, caries but significant with necrotic puples.

plates (Oxoid, England), $6.5 \% \mathrm{NaCl}$ solution and bileesculin tube agar. Every growth showing gram-positive cocci, positive bile-esculin, positive $6.5 \% \mathrm{NaCl}$ tests, catalase-negative and appearing as yellow, small/medium in size on CLED agar (Oxoid, England) were recorded tentatively as Enterococcus isolates. E. faecalis ATCC 29212 was included as a positive control through out the study.

\section{Biochemical detection of $E$. faecalis isolates}

All tentative Enterococcus isolates were subcultured on brain heart infusion agar plates (Oxoid, England) and tested using biochemical Remel system (RapID ${ }^{\mathrm{Tm}}$ STR system, USA) to confirm their identity as E. faecalis.

\section{Hemolysin and gelatinase activities}

E. faecalis isolates were assessed for hemolytic activity on blood base agar (Oxoid, England) supplemented with 5\% (v/v) human blood. A single colony was cultured onto blood agar plates and its hemolytic activity was determined by presence of clear zone around the colonies ( $\beta$ hemolysis) as reported by Creti et al. [15]. Gelatinase activity was assessed by inoculation of single colonies of each isolate as spot form on $12 \%$ gelatin plates (Defico, USA). The plates were incubated at room temperature for
$48 \mathrm{hrs}$. Gelatinase activity was evident by the presence of liquefied zone around the colonies. Serratia mercenses ATCC 13880 was used as a positive control for gelatinase production test.

\section{Antimicrobial susceptibility test}

Susceptibility of E. faecalis isolates to 9 antimicrobial agents was determined using disc diffusion method according to NCCLS (now CLSI) guidelines [16].

\section{Detection of $E$. faecalis in oral rinse sample by PCR}

DNA extraction was performed using Wizard Genomic DNA Purification Kit (Promega, USA), according to manufacturer's instructions. The DNA extractions were used for detecting the specific gene 16S rRNA of E. faecalis in oral rinse samples [17]. PCR conditions were accomplished by a PCR thermocycler (MJ research- INC, USA), and were as follows: 15 min initial enzyme activation/ DNA denaturation step at $95^{\circ} \mathrm{C}$ followed by 35 consecutive cycles at $94^{\circ} \mathrm{C}$ for $20 \mathrm{~s} ; 68^{\circ} \mathrm{C}$ for $45 \mathrm{~s} ; 72^{\circ} \mathrm{C}$ for $15 \mathrm{~s}$. PCR products were analyzed by electrophoresis using $2 \%$ agarose gel (Promega, USA) containing ethidium bromide in $1 \times$ TBE buffer, and run for $1 \mathrm{hr}$ with $70 \mathrm{~V}$, and visualized by UV Trans-illuminator (UVP) and Gel

Table 3: Presence of I6S rRNA gene and prevalence of esp, cylA, ace, efaA genes among the 8 oral E. faecalis isolates detected by PCR.

\begin{tabular}{|c|c|c|c|c|c|}
\hline Isolate No. & I6S rRNA & esp & cylA* & ace & efaA \\
\hline 3 & + & - & - & + & + \\
\hline 44 & + & - & - & + & + \\
\hline 1 & + & - & - & + & + \\
\hline 2 & + & - & + & + & + \\
\hline 6 & + & - & - & + & + \\
\hline 12 & + & - & - & + & + \\
\hline 18 & + & - & - & + & + \\
\hline 59 & + & - & + & + & + \\
\hline Total strains No. (\%) & $8(100 \%)$ & $0(0.0 \%)$ & $2(25 \%)$ & $8(100 \%)$ & $8(100 \%)$ \\
\hline
\end{tabular}

\footnotetext{
*Two isolates expressed hemolytic activity in vitro
} 


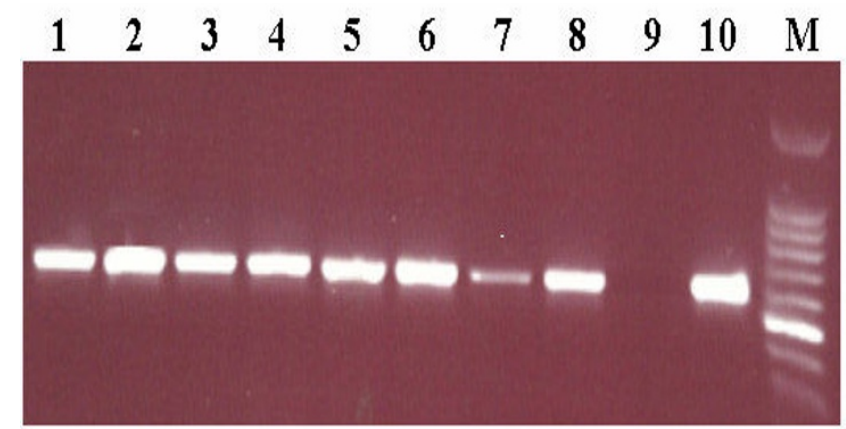

Figure I

Distribution of efaA gene among the 8 oral E. faecalis isolates. M, 100 bp DNA marker; Lane I, efaA (688 bp); positive control ( $E$. faecalis ATCC 292I2); Lane 2, efaA negative control; Lanes 3 to 10 , positive to efaA among oral $E$. faecalis isolates.

Documentation System (UVP). The same PCR reaction was tested with each single control strain of E. faecium and S. mutans which were isolated from other clinical specimens at JUH, and by using E. faecalis ATCC 29212.

The PCR test used, gave a negative result with DNA extracted from E. faecium and S. mutans. Also, DNA extraction of recovered and identified E. faecalis isolates were confirmed using the same DNA extraction and PCR procedure under the same conditions used for oral rinse specimens (Table 4).

\section{Detection of $E$. faecalis putative virulence genes}

DNA of E. faecalis isolates was prepared by suspending a loop full of overnight growth colonies grown on blood agar in a tube that contained $500 \mu \mathrm{l}$ sterile distilled water, followed by boiling for $10 \mathrm{~min}$ and then centrifuged at $12,000 \mathrm{~g}$ for $6 \mathrm{~min}$. An aliquot of the supernatant $(5 \mu \mathrm{l})$ was used as the template in a final volume of $25 \mu \mathrm{l}$ PCR mixture [15]. PCR amplification for the following genes: collagen binding protein (ace), endocarditis antigen

Table 4: Antimicrobial susceptibility of 8 E. faecalis by disc diffusion method

\begin{tabular}{cc}
\hline Antimicrobial agents & No. (\%) of isolates susceptible \\
\hline Ampicillin & $8(100)$ \\
Chloramphenicol & $8(100)$ \\
Ciprofloxacin & $8(100)$ \\
Teicoplanin & $8(100)$ \\
Vancomycin & $8(100)$ \\
Erythromycin & $5(62.5)^{*}$ \\
Gentamycin & Null \\
Clindamycin & Null \\
Oxacillin & Null \\
\hline
\end{tabular}

Harbored only ace, efaA genes.
(efaA), haemolysin activator $(c y l A)$, and a surface protein (esp) were prepared as uniplex in a $25 \mu \mathrm{l}$ final reaction volume. Table 5 shows the primers used in the study $[15,17,18]$.

Samples were amplified in a PCR thermal cycler (MJ research- INC, USA), by heating for $5 \mathrm{~min}$ at $95^{\circ} \mathrm{C}$, followed by 30 cycles of $95^{\circ} \mathrm{C}$ for $60 \mathrm{~s}, 58^{\circ} \mathrm{C}$ for $60 \mathrm{~s}\left(63^{\circ} \mathrm{C}\right.$ for $e s p$ ) and $72^{\circ} \mathrm{C}$ for $60 \mathrm{~s}$, and a final step of $72^{\circ} \mathrm{C}$ for 10 min. PCR products were analyzed in $0.8 \%$ agarose gel electrophoresis (containing $0.5 \%$ ethidium bromide in $1 \times$ TBE buffer) which run for 50 minutes by 80 voltages using horizontal electrophoresis apparatus, and visualized by Gel Documentation System (UVP, USA). E. faecalis ATCC 29212 was used as a positive control in each PCR run to detect $c y l A$, ace, efaA genes, and to test DNA prepared from certain E. faecalis strains (EFS121, EFS87, EFS16, EFS27B, EFSU85, and EFS118) which were obtained from Dr. Roberta Creti (Dipartimeno Di Malattie Infecttive, Parassitarie ED Immunomediate, Istituto Superiore di Sanità, Viale Regina Elena, 299-00161 Rome, Italy). These DNA preparations were used as a positive control for esp gene along with $1 \mathrm{~Kb} / 100$ bp Ladder marker (promega, USA).

\section{Statistical analysis}

$Z$ test was used to compare the prevalence of E. faecalis in patients group and control group according to the following equation:

$Z=P_{1}-P_{2} / \sqrt{ } P(1-P)\left(1 / n_{1}+1 / n_{2}\right) . P<0.05$ was considered statistically significant.

\section{Discussion}

The present study shows that E. faecalis isolates were recovered from Jordanian patients in association with one or more of the following dental diseases; caries, gingivitis, plaque-induced gingivitis, and endodontic infection, and in a significant rate $(7.3 \% ; \mathrm{P}=0.031)$ compared to healthy control persons (Zero). Despite the fact that generally PCR is more sensitive than culture method in detection of bacteria in clinical specimens, this study has not detected any positive E. faecalis using direct oral rinse specimens. Sedgley CM et al., 2005 (19) found that a quantitative real-time PCR reported a higher incidence of E. faecalis in oral rinse samples than culture techniques and afforded greater sensitivity. The study revealed that poor oral hygiene, gingivitis and necrotic pulps appear to be important predisposing factors for infection with $E$. faecalis (Table 2). A recent similar study from USA has isolated E. faecalis from $11 \%$ of oral rinse samples of patients receiving endodontic treatment, but only $1 \%$ of $E$. faecalis was recovered from dental students with no history of endodontic treatment [14]. Enterococci are able to colonize the oral cavity, particularly in patients with periodontitis or root canal infections associated with oral mucosal 
Table 5: E. faecalis primers used in the study

\begin{tabular}{|c|c|c|c|}
\hline Gene & Sequence & Product size (bp) & Reference \\
\hline E. faecalis $16 \mathrm{~S}$ rRNA & $\begin{array}{l}\text { EfI6SF 5' - CCGAGTGCTTGCACTCAATTGG - 3' } \\
\text { EfI6SR 5' - CTCTTATGCCATGCGGCATAAAC - 3' }\end{array}$ & 138 & 17 \\
\hline Esp & $\begin{array}{l}\text { 5'-TTGCTAATGCTAGTCCACGACC-3' } \\
\text { 5'-GCGTCAACACTTGCATTGCCGA-3' }\end{array}$ & 932 & 18 \\
\hline cylA & $\begin{array}{l}\text { 5'-GACTCGGGGATTGATAGGC-3' } \\
\text { 5'-GCTGCTAAAGCTGCGCTTAC-3' }\end{array}$ & 688 & 15 \\
\hline ace & $\begin{array}{l}\text { 5'-GGAATGACCGAGAACGATGGC-3' } \\
\text { 5'-GCTTGATGTTGGCCTGCTTCCG-3' }\end{array}$ & 616 & 15 \\
\hline efaA & $\begin{array}{l}\text { 5'-GCCAATTGGGACAGACCCTC-3' } \\
\text { 5'-CGCCTTCTGTTCCTTCTTTGGC-3' }\end{array}$ & 688 & 15 \\
\hline
\end{tabular}

lesions and in immuno-compromised patients [20,21]. Also, E. faecalis is the most commonly isolated species from root canals samples with endodontic failure $[2,21,22]$. E. faecalis has been often isolated in pure culture or as a predominant organism in previously rootfilled teeth with periapical lesions or chronic apical periodontitis $[3,19,23,24]$. Furthermore, it has been found that this organism persistently infected root canal where calcium hydroxide medication is ineffective [25].

This study shows that the production of hemolysin and gelatinase as putative virulence determinants were not always expressed by $E$. faecalis isolates in association with dental diseases, since only $25 \%$ of $E$. faecalis isolates expressed hemolysin and $37.5 \%$ gelatinase activity in vitro, respectively. Two studies carried by Sedgley et al. $[14,23]$ reported different results with hemolysin production, first study has proved that $36 \%$ of the E. faecalis strains recovered from endodontic patients produced hemolysin, while the second has not detected production of hemolysin in any enterococcal isolates from endodontic cases. Also, Sedgley et al. [22] found that gelatinase gene (gelE) was detected in all endodontic isolates of $E$. faecalis while expressed gelatinase activity was observed in two thirds of the isolates. These studies concluded that evidence of potential virulence factors were identified in endodontic Enterococcus spp., specifically production of gelatinase and response to pheromones. Other studies indicated that expression of gelatinase gene contributed to the increased dissemination of E. faecalis in high-density environments and was associated with increased adhesion of E. faecalis to dentine in vitro $[26,27]$.

The present study has shown that both ace and efaA genes were present in all $E$. faecalis isolates, while cylA gene was detected only in two isolates, and all isolates were negative for esp gene which is mostly found in E. faecalis strains isolated from urinary tract infections [18].

A recent molecular-based study indicated that virulence determinants efaA and ace genes has been found in all $E$. faecalis isolates from root canal of endodontic patients, whereas esp gene was present in (58\%) and cylA gene in $(19.4 \%)$ of the isolates [11]. These results are in agreement with our results except for esp gene. In general, the expression of hemolysin and gelatinase activity or their genes along with the occurrence of other virulence genes (esp, cylA, ace, efa A) in E. faecalis strains varied widely from one study to another and probably due to the difference in their clinical and geographic origins $[5,9,11,26$ 29]. Furthermore, neither esp nor gelatinase seemed to be required for biofilm formation; both $E$. faecalis and $E$. faecium did not show a correlation between the presence of either esp or the production of gelatinase and biofilm formation [30]. It appears that many environmental and genetic factors may be associated with the production of biofilm by E. faecalis [31].

In recent years, enterococci have received increasing attention because of the development of resistance to multiple antimicrobial drugs and its common prevalence in nosocomial infections. Vancomycin-resistant enterococci (VRE) probably represent currently the most serious challenge among many microbes with antibiotic resistance causing human infections [32]. Our results showed that all $E$. faecalis isolates were susceptible to chloramphenicol, ampicillin, vancomycin, ciprofloxacin, and teicoplanin, but the isolates were much less susceptible to erythromycin. A study by Pinheiro et. al. [12] showed that E. faecalis isolates from oral specimens were completely susceptible in vitro to amoxicillin, amoxicillin-clavulanic acid, vancomycin and to less extent susceptible to erythromycin, moxifloxacin, chloramphenicol, tetracycline, doxycycline, and ciprofloxacin. The susceptibility result of our limited number of $E$. faecalis isolates indicated higher frequency of resistance rates than those reported in recent studies from western countries [11-13]. Moreover, our susceptibility result correlate well with the high prevalence of resistance among clinical and community Staphylococcus aureus isolates in Jordan [33]. 
In conclusion, this study shows that all E. faecalis isolates are associated with various dental diseases especially necrotic pulps in patients and they carried both collagen binding protein and endocarditis antigen genes.

\section{Competing interests}

The authors declare that they have no competing interests.

\section{Authors' contributions}

AAS and ND-O contributed to the design of all experiments and writing the manuscript. ND-O and OAH examined all patients and control persons and collected the oral specimens. RS performed all laboratory tests and cowrote the manuscript.

\section{Acknowledgements}

This study was partly supported by grant from the Faculty of Graduate Studies, University of Jordan, Amman, Jordan. The authors thank Dr. Roberta Creti (Laboratory of Bacteriology, Institute of Special Hygiene, University of La Sapienza, Rome, Italy) for sending DNA prepared from certain $E$. faecalis strains which was used as positive control for esp gene.

\section{References}

I. Sedgley C, Buck G, Appelbe O: Prevalence of Enterococcus faecalis at multiple oral sites in endodontic patients using culture and PCR. J Endod 2006, 32: 104-109.

2. Johnson EM, Flannagan SE, Sedgley CM: Coaggregation interactions between oral and endodontic Enterococcus and bacterial species isolated from persistent apical periodentitis. J Endod 2006, 32:946-950.

3. Pinheiro ET, Gomes BP, Ferraz CC, Sousa EL, Teixeira FB, SouzaFilho F): Microorganisms from canals of root-filled teeth with periapical lesions. Int Endod J 2003, 36: I-II.

4. Rams T, Feik D, Young V, Hammond B, Slots J: Enterococci in human periodontitis. Oral Microbiol Immunol 1992, 7:249-252.

5. Kayaoglu G, Ørstavik D: Virulence factors of Enterococcus faecalis: Relationship to endodontic disease. Int Am Asso for Dent Res 2004, I 5:308-320.

6. Gomes BPFA, Pinheiro ET, Gade-Neto CR, Sousa EL, Ferraz CC, Zaia AA, Teixeira FB, Souza-Filho FJ: Microbiological examination of infected dental root canal. Oral Microbiol Immunol 2004, 1 9:7I-76.

7. Reynaud af Geijersstam A, Culak R, Molenaar L, Chattaway M, Røslie E, Peciuliene V, Haapasalo M, Shah HN: Comparative analysis of virulence determinants and mass spectral profiles of Finnish and Lithuanian endodontic Enterococcus faecalis isolates. Oral Microbiol Immunol 2007, 22:88-94.

8. Tendolkar PM, Baghdavan As, Shankar N: Putative surface proteins encoded within a novel transferable locus confer a highbiofilm phenotype to Enterococcus faecalis. J Bacteriol 2006 , 188:2063-72.

9. Archimbaud C, Shankar N, Forestier C, Baghdayan A, Gilmore MS, Charbonne $F$, Joly B: In vitro adhesive properties and virulence factors of Enterococcus faecalis strains. Res Microb 2002, I 53:75-80.

10. Eaton TJ, Gasson MJ: Molecular Screening of enterococcus virulence determinants and potential for genetic exchange between food and medical isolates. Appl Environ Microbiol 200I, 67:1628-1635

II. Reynaud Af, Geijersstam AH, Ellington MJ, Warner M, Woodford N, Haapasalo M: Antimicrobial susceptibility and molecular analysis of Enterococcus faecalis originating from endodontic infections in Finland and Lithuania. Oral Microbiol Immunol 2006, 21:164-168.

12. Pinheiro ET, Gomes BPFA, Drucker DB, Zaia AA, Ferraz CCR, SouzaFilho Fl: Antimicrobial susceptibility of Enterococcus faecalis isolated from canals of root filled teeth with periapical lesions. Int Endod J 2004, 37:756.
13. Dahle'n G, Samuelsson W, Molander A, Reit C: Identification and antimicrobial susceptibility of enterococci isolated from the root canal. Oral Microbiol Immunol 2002, I 5:309-3 I 2.

14. Sedgley CM, Lennan SL, Clewell DB: Prevalence, phenotype and genotype of oral enterococci. Oral Microbiol Immunol 2004, 19:95-101.

15. Creti R, Imperi M, Bertuccini L, Fabretti F, Orefici G, Di Rosa R, Baldassarri $L$ : Survey for virulence determinants among Enterococcus faecalis isolated from different sources. I Med Microb 2004, 53:13-20.

16. NCCLS: Performance Standards for Antimicrobial Susceptibility Testing: 14th Informational Supplements. NCaS document M I00-S I 4, Wayne, PA: NCaS 2004.

17. Sedgley CM, Molander A, Flannagan SE, Nagel AC, Appelbe OK, Clewell DB, Dahlen G: Virulence, phenotype and genotype characteristics of endodontic Enterococcus. Oral Microbiol Immunol 2005, 20:10-19.

18. Shankar N, Lockatell CV, Baghdyan AS, Drachenberg C, Gilmore MS, Johnson DE: Role of Enterococcus faecalis surface protein Esp in the pathogenesis of ascending urinary tract infection. Infect Immun 200I, 69:4366-4372.

19. Sedgley CM, Nagel AC, Shelburne CE, Clewell DB, Appelbe O, Molander A: Quantitative real-time PCR detection of oral Enterococcus faecalis in humans. Arch Oral Biol 2005, 50(6):575-83.

20. Pinheiro ET, Anderson MJ, Gomes BPFA, Drucker DB: Phenotypic and genotypic identification of enterococci isolated from canals of root-filled teeth with periapical lesions. Oral Microbiol Immunol 2006, 21:137-144.

21. Guven Kayaoglu, Orstakavik D: Virulence enterococcus faecalis: relation to endodontic disease. Crit Rev Oral Biol Med 2004, I 5:308-320.

22. Ferrari PHP, Cai S, Bombana AC: Effect of endodontic procedures on enterococci, enteric bacteria and yeasts in primary endodontic infections. Int Endod J 2005, 38:372-380.

23. Sedgley C, Nagel A, Dahlen G, Reit C, Molander A: Real-time quantative polymerase chain reaction and culture analyses of Enterococcus faecalis in root canals. J Endod 2003, 32(3): $173-177$

24. Molander A, Reit C, Dahlen G, Kvist T: Microbiological status of root-filled teeth with apical periodontitis. Int Endod J 1998, 3I:I-7.

25. Nakajo K, Komori R, Ishikawa S, Ueno T, Suzuki Y, Iwami Y, Takahashi N: Resistance to acidic and alkaline environment in the endodontic pathogen Enterococcus faecalis. Oral Microbio Immunol 2006, 21:283-288.

26. Hubble TS, Hatton JF, Nallapareddy SR, Murray BE, Gillespie MJ: Influence of Enterococcus faecalis proteases and the collagenbinding protein, Ace, on adhesion to dentin. Oral Microbiol Immunol 2003, 18:121-126.

27. Waters CM, Antiporta MH, Murray BE, Dunny GM: Role of the Enterococcus faecalis GelE protease in determination of cellular chain length, supernatant pheromone levels, and degradation of fibrin and misfolded surface proteins. J Bacteriol 2003 , 185:3613-3623

28. Coque TM, Patterson JE, Steckelberg JM, Murray BE: Prevalence of hemolysin, gelatinase, and aggregation substance among enterococci isolated from patients with endocarditis and other infections and from feces of hospitalized and community-based persons. J Infect Dis 1995, I7 I: 1223-1229.

29. Elsner HA, Sobottka I, Mack D, Glaussen M, Laufs R, Wirth R: Virulence factors of Enterococcus faecalis and Enterococcus faecium blood culture isolates. Europ J Clin Microbiol Infect Dis 2000, 19:39-42.

30. Di Rosa R, Creti R, Venditti M, D'Amelio R, Arciola CR, Montanaro $L$, Baldassarri $L$ : Relationship between biofilm formation, the enterococcal surface protein (Esp) and gelatinase in clinical isolates of Enterococcus faecalis and Enterococcus faecium. FEMS Microbiol Lett 2006, 256: | 45-50.

31. Mohamed I Jamal A, Huang David B: Biofilm formation by enterococci. J Med Microbiol 2007, 56:158I-I 588.

32. Willems RJ, Top J, van Santen M, Robinson DA, et al.: Global spread of vancomycin-resistant Enterococcus faecium fro distinct nosocomial genetic complex. Emerg Infect Dis 2006, I I:82 I-828.

33. Al-Zu'bi E, Bdour S, Shehabi AA: Antibiotic resistance patterns of mecA-positive Staphylococcus aureus isolates from clini- 
cal specimens and nasal carriage. Microb Drug Resist 2004, 10:32I-324.

\section{Pre-publication history}

The pre-publication history for this paper can be accessed here:

http://www.biomedcentral.com/1472-6831/8/17/prepub

Publish with Bio Med Central and every scientist can read your work free of charge

"BioMed Central will be the most significant development for disseminating the results of biomedical research in our lifetime." Sir Paul Nurse, Cancer Research UK

Your research papers will be:

- available free of charge to the entire biomedical community

- peer reviewed and published immediately upon acceptance

- cited in PubMed and archived on PubMed Central

- yours - you keep the copyright 